\title{
The Use of Gold in Dentistry
}

\author{
AN HISTORICAL OVER VIEW. PART I
}

\author{
J. A. Donaldson \\ British Dental Association Museum, London, U.K.
}

\begin{abstract}
Gold was first used in dentistry over 2500 years ago, and its dental applications have increased steadily, especially during the past 100 years, to the point where they now absorb over 80 tons of gold per annum. The course of these developments is outlined in this review, Part II of which will appear in the next issue of Gold Bulletin.
\end{abstract}

Where and when gold was first used in connection with the care of the teeth as opposed to their decoration are matters of doubt and disagreement. A plausible hypothesis by Humphreys (1) proposed that man's change from a way of life entirely dependent on hunting to one dependent on food production from crops and herds, extended his life span by one or two decades so that the loosening of incisor teeth as a result of degeneration of surrounding tissues - a feature of advancing age - became a problem. Humphreys suggested that with the development of early gold metallurgy the possibility arose of holding loose incisor teeth in place by gold wire which was twisted around them and the firmer canines.

\section{Early Use of Gold Wire}

Several dental historians have referred to the discovery by Junker (2), in 1914, in a burial shaft at Giza, of two molar teeth held together by a gold wire, along with articles that he believed to date from the late 4 th or the 5th Dynasty in the third millenium B.C. (This item is now in the Pelizaeus Museum in Hildesheim (3)). Some have based on this one discovery a belief in the existence in ancient Egypt of prosthetic dentistry; others, such as Filce Leek (4) who suggested that the find might be part of an amulet, have disagreed. A recent re-examination of the available evidence by Hoffmann-Axthelm (5) indicates that such examples of binding teeth with gold wire as have been found in skulls excavated from Egyptian burial grounds were not the result of treatment on living persons but rather the consequence of steps taken in the course of preparing corpses for embalming. Other examples of teeth bound together by gold wire were found in a pre-Columbian tomb at Esmeraldas, Ecuador, and in Etruscan burials (l).

The Etruscans appear, on such evidence as exists at present, to have been the first, as early as the seventh centry B.C., to insert a substitute tooth by replacing the gold wire by gold bands in front of and behind the incisor teeth on each side of the gap, drilling a hole through both bands and the new tooth, and inserting a gold wire as a rivet. Many examples of such prostheses can be seen in museums in Italy and elsewhere. In some cases the 'artificial' tooth is the lost tooth with its root cut off, in others it is a portion of a tooth from a calf or cow. In a few instances, an artificial tooth has been fashioned from gold.

Few examples of Roman dental prostheses for which gold was used have survived, owing to the widespread Roman custom of cremating the dead. However, the fact that the Law of the Twelve Tables, written in Rome during the fifth century B.C., specifies at the close of a rule prohibiting the burial of gold articles with corpses the exception that '.. it shall not be unlawful to bury or burn it with the gold with which the teeth may perchance be bound together' is widely taken as supporting the view that prosthetic dentistry was practised at the time (6). Indeed, the Romans inherited many arts and crafts, including those of dental prosthesis, from their Etruscan neighbours who during the sixth century B.C. ruled Rome. Celsus, in his 'De re medica', describes the use of gold wire to bind to adjacent firm teeth those teeth which had been damaged by a blow or other accident.

The Greeks also practised cremation and little evidence of their use of gold for dental purposes has been found. However, the few dental appliances exhibited in Greek museums are strikingly similar to Etruscan work.

The practice of providing support for incisor teeth that had become loose was known to the Arabs and was described by Albucasis who lived in the latter half of the eleventh century A.D. His treatise on surgery exists in several manuscript versions and contains references to diseases of the teeth and gums, as well as a recommendation that when teeth have 


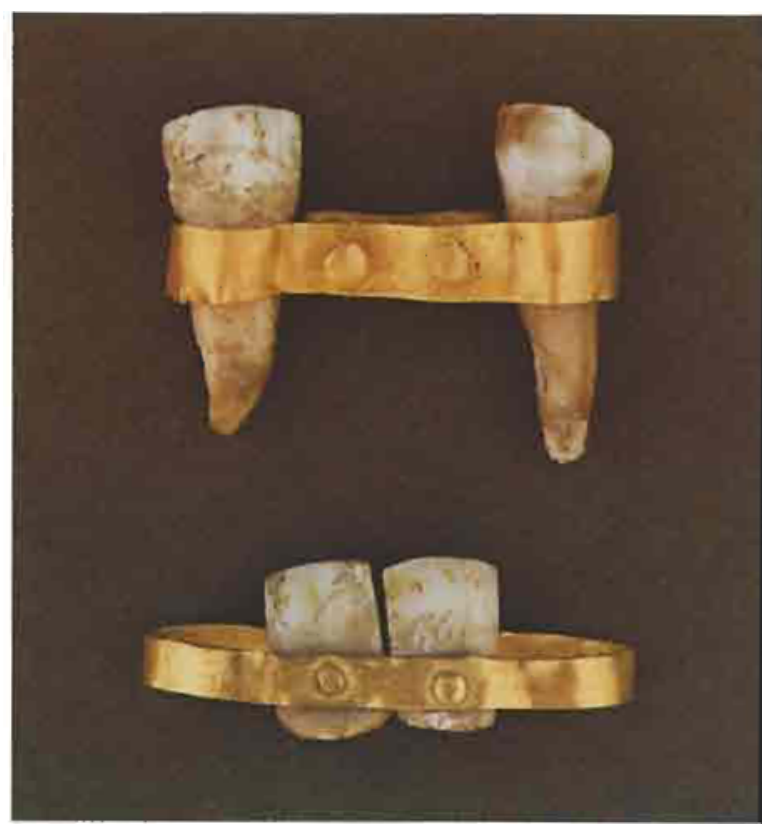

become loose after a blow or fall, so that the patient cannot bite his food with them, they should be bound with gold or silver wire to make them firm. Albucasis states that gold is to be preferred as being unalterable, while silver turns green in a few days. It was for this reason that gold was used in the mouth by the Etruscans and the other peoples mentioned above: its chemical inertness enabled it to withstand the corrosive action of the oral fluids which would have been so evident when other metals and alloys known at the time were used.

\section{Later Use of Gold Wire}

Other early writers on dentistry have described applications of gold wire in the mouth. Ryff (7) illustrated its use to reduce and fix a fractured mandible. Paré (8) recorded the attachment by gold or silver wire of an artificial tooth made of bone or ivory to adjacent natural teeth. Fauchard (9), in his important work which may justly be called the first scientific book on dentistry, described how 'loose teeth can be tightened by turns of gold wire' and gave detailed instructions for annealing the wire in the fire, throwing it into vinegar to restore its colour and for its careful application to the teeth. Mouton (10) in the first book devoted to prosthetic dentistry, gave an account of his method of retaining small dentures carved from ivory by spring clasps of round gold wire which encircled adjoining teeth.

Gold wire continued to be used for purposes such as tempory splinting of teeth loosened accidentally until well into the present century and it was applied during World War I for inter-dental wiring in the treatment of jaw fractures. During the past 40 years,
Two Etruscan dental prostheses made by passing thin strips of gold round teeth on each side of a space from which a tooth or teeth had been lost and rivetting the strip so as to hold the substitute teeth in place. In one case, the abutment teeth are present, but the artificial tooth is lost, and in the other case, the two substitute teeth, portions of an animal tooth, remain

Photograph by courtesy of the Merseyside County Muscums, Liverpool

however, it has been increasingly replaced by stainless steel wire.

\section{Filling Teeth with Gold Foil}

The first printed book on dentistry, entitled 'Artzney Büchlein' ('The Little Pharmacopaeia'), was published by Michael Blum in Leipzig in 1530 . Under this title or as 'Zene Artznei' ('Dental Medicine') it appeared in some fifteen editions issued by various German publishers in the sixteenth century. It is largely a compilation from earlier manuscript works by several authors. Chapter 5 of the 1536 edition which is kept at the British Dental Association Library, after a description of 'corrosion' or decay of the teeth, advises on its treatment:

'Scrape and clean the hole and the area of decay with a fine small chisel or a little knife or a file, or with another suitable instrument, and then to preserve the other part of the tooth, fill the cavity with gold leaves'.

This advice is attributed to Mesue, one of those from whose writings the book is compiled, but there is doubt as to his identity and no existing work by a person of this name is known in which reference is made to the use of gold. foil to restore decayed teeth. However, that the procedure described by Blum was indeed widespread in the Renaissance period is confirmed by Giovanni d'Arcoli (11), who wrote that teeth could be filled with gold leaf after cleansing of the cavity with acid, and by Giovanni da Vigo (12) who referred to the use of gold foil for this purpose.

\section{Nineteenth Century Advances}

Methods of restoring carious cavities in teeth by means of gold foil did not progress appreciably, however, from the period of these references until the nineteenth century. Then, first as a result of a better knowledge of the structure of teeth and the process of their decay, and secondly as a consequence of the invention of mechanical means for cavity preparation, advance was rapid.

Robert Arthur, who practised in turn in several American towns, made many improvements to the art of filling teeth with gold. In the opening chapters of his 'Treatise on the Use of Adhesive Gold Foil' (13), he presented a critical account of the common 


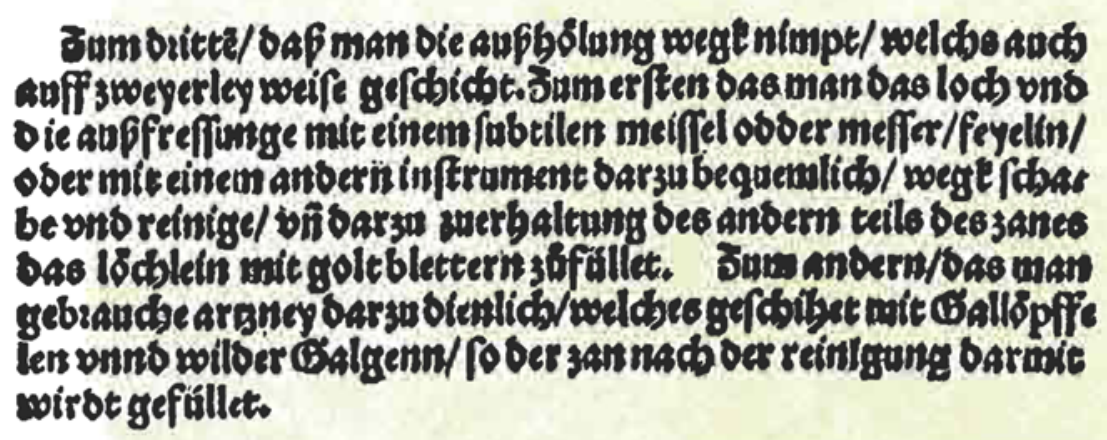

\begin{abstract}
Michael Blum's 'Artzney Büchlein' is the first printed book on dentistry. Chapter 5 of the 1536 edition, published 6 years after the original edition, briefly describes the preparation of decayed teeth for the filling of cavities in them with gold leaf. A translation of the relevant sentence, the second in the paragraph shown here, is given in the text of this article

Reproduced by courtesy of the British Dental Association Library, London
\end{abstract}

methods of the period. The foil was cut into strips which were used as such, or rolled into 'ropes', or folded into 'tapes' and placed round the circumference of the cavity. More strips, ropes or tapes were added from the centre and space was made for further additions by pushing a wedge-shaped instrument into the partially filled cavity to force the gold against the walls until a degree of compaction was achieved that was considered satisfactory. Other dentists cut the ropes or tapes into short lengths or small pieces. One such piece was forced into a corner at the bottom of the cavity, and others were placed around it, one by one, to cover the bottom; the filling was then built up, layer by layer, from further pieces.

'Sponge' or 'crystal' gold was another form of dental gold, then only recently introduced, which was examined by Arthur in his critique before he went on to describe the superiority of his own 'adhesive foil'. Material of the former type originated in England and was dismissed by Arthur as useless. Another variety was invented by A. J. Watts in the U.S.A. and is described in a patent specification as made by dissolving the mercury from a fluid amalgam of gold by means of nitric acid. This left the gold in a finely divided, easily manipulated state that could be bonded into a solid mass by pressure. The aim of Watts' invention was to reduce the tedium of filling large cavities piece by piece or strip by strip with foil, by inserting gold in the new form in bigger portions and compacting it rapidly. In practice, the technique was difficult and, as Arthur rightly pointed out, pressure applied to a large piece of the sponge or crystal gold compacted it only superficially, leaving soft, weak areas beneath its surface. However, the use of gold in these or related forms was not then discontinued. Similar products made by a number of methods were introduced from time to time and continued to find application almost to the middle of this century.
Arthur's principal contributions to the technique were based upon his exploitation of the cohesive properties of clean, annealed gold foil. He passed each portion of foil through a flame before inserting it in the cavity and devised methodical routines for filling cavities of different shapes with metal of consistent density by using plugging instruments with small working ends and so exerting high pressures to compact the gold and weld it into a solid mass. Arthur was not the only dentist to exploit the cohesive properties of annealed gold foil, others did so at about the same time. According to Boyes (14), for example, James Hogue, an Edinburgh practitioner, was using it in 1850. Nevertheless, to Arthur belongs the credit of developing a well thought out practical method, of demonstrating this to a professional society in 1855 and of publishing a book on the subject in 1857 .

Pure gold of many descriptions - sponge, crystal, matt, cohesive and non-cohesive among others - inserted in small portions and laboriously built up to plug the cavity continued to be used for the next hundred years. Each operator chose the form best suited to his skill or the type of cavity he had to fill. The presidential address by C. Spence Bate at the 1883 annual meeting of the British Dental Association, in Plymouth, entitled 'A Review of the Scientific Progress of Dental Surgery from 1771 to $1883^{\prime}$ (15), contains the passage:

\footnotetext{
'We must congratulate ourselves on the great improvement that has taken place in the power of retaining diseased teeth and restoring to usefulness such as would, a few years ago, have been considered hopelessly irrecoverable. The extent of this process of repair can best be understood by saying that, independent of amalgam and cement stoppings, 20000 ounces $[620 \mathrm{~kg}$ ] of fine gold is annually used in filling teeth ...
}

Unfortunately, there is no indication whether this 


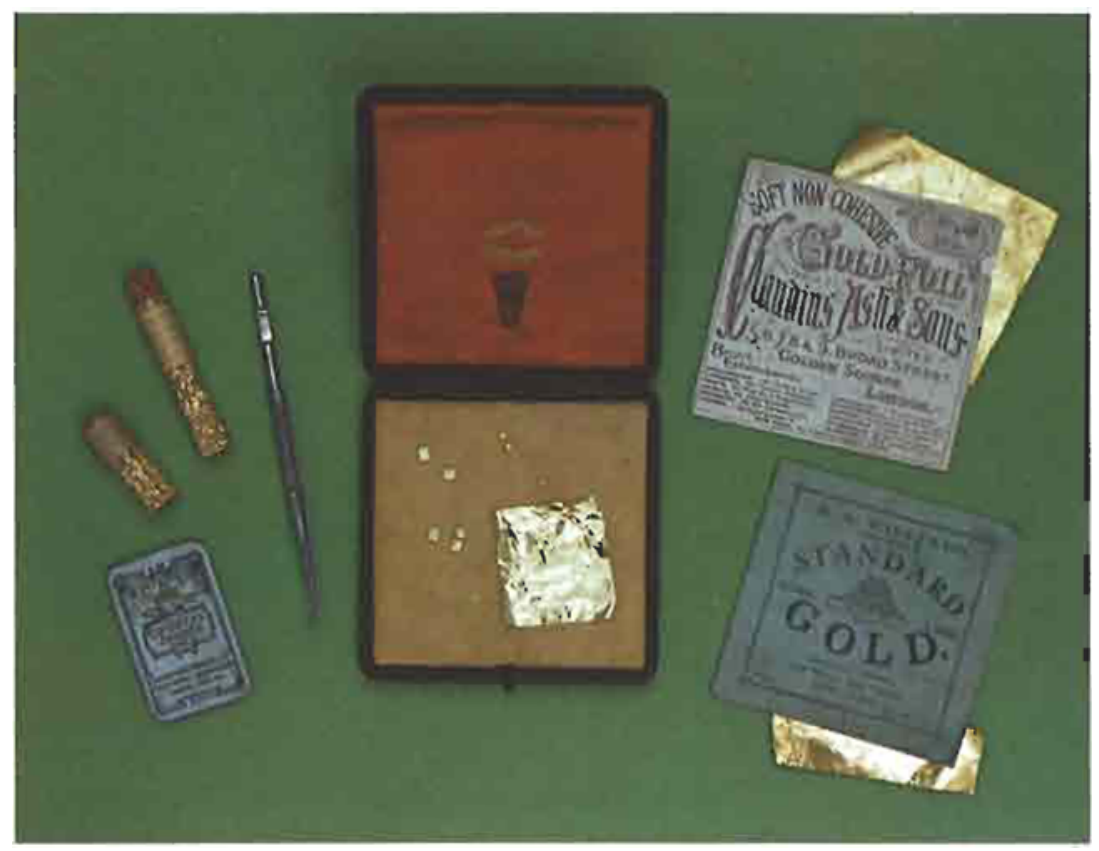

lllustrated here are but some of the many forms of gold available for dental fillings at the turn of this century. The foil was manipulated with the tweezers and kept to hand on the chamois leather 'gold pad'

was the amount used world-wide or whether it was only that used in Britain.

As a cheaper form of restoration than one entirely of pure gold, for use in four-walled cavities (that is, those involving one surface of a tooth), some operators placed a sheeet of tin foil between two sheets of non-cohesive gold foil and rolled their ropes or cyclinders from the composite material.

\section{Gold Foil Filling Instruments}

While a limited number of forms of gold was developed for the filling of cavities, dentists indulged their noted individualism by designing plugging instruments until a vast armamentarium existed and some dental depots, at one time, stocked hundreds of patterns. The need was to apply a high compressive load per unit area to the foil and, naturally, methods were devised to increase this load by impact and to speed the process by mechanical means. In the late 1850's, John Tomes, in England, introduced his simple mallet, made for him by the dental instrument-maker Jean Evrard. To judge from the number surviving in museums and private collections, it must have had considerably popularity. It

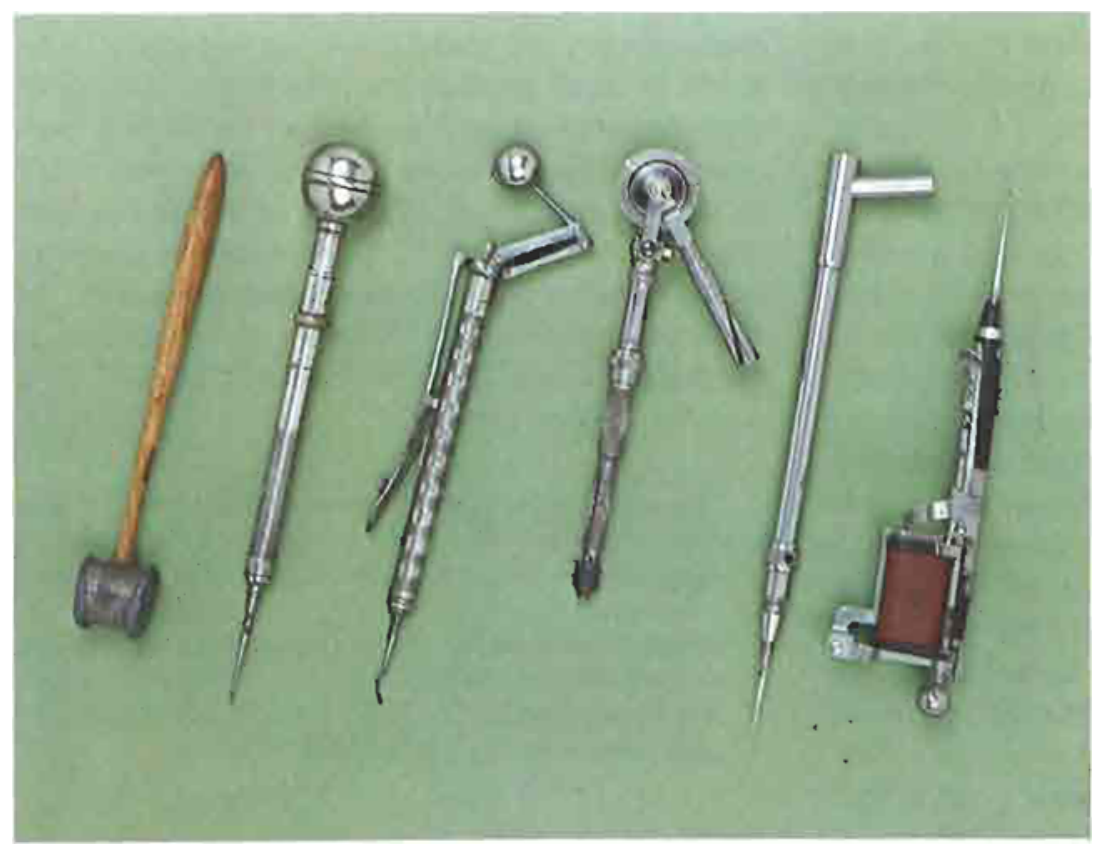

Mallets for compacting cohesive gold foil into a solid mass: lead filled hand mallet, Goode's spring mallet, Kirby's lever action nullet, Bonwill's mechanical mallet for attachnent to a foot engine, Kirby's pneumatic mallet, and Webb's improved Bouwill electromagnetic mallet Photograph by courtesy of the British Dental Association Museum, London 
was followed by many other mechanical hand mallets in Britain, on the Continent and in the U.S.A. Most used the principle of a weight pulled against a spring, sometimes through a system of levers, and then suddenly released to strike a plugging instrument or point.

It is reputed that it was hearing a Morse telegraph sounder working that led W. G. A. Bonwill to design his electromagnetic mallet which, in a form much improved by $M$. H. Webb and introduced in 1877 , enjoyed large sales in many countries. A description of Webb at work, written by his patient W. H. Trueman, another dentist, and cited by B. L. Thorpe (16) gives some idea of the endurance required of both patient and operator:

'Dr. Webb ... did in my mouth his last but one heavy job, filling four upper incisors using four books, one half ounce of gold foil. I went to Lancaster, arriving on a Monday afternoon; he had done the preliminary work in Philadelphia. He began the next morning and for two days I was in the chair, my mouth dammed from 8.30 a.m. to 5 p.m. I did not get out and Webb was at me all the time except fifteen minutes for lunch. I went hungry, not even a sip of water as we were both anxious that there should be no mishap. Another day he worked on me from three to five hours and finished about ten o'clock Sunday morning, aitogether six days to fill four teeth.'

Not only did the introduction of the foot engine (or 'foot drill') in 1871 stimulate the invention of forms of chuck called 'handpieces' in which burs, drills, abrasive wheels, discs and points, and small revolving tools of other kinds could be used at different angles to prepare teeth for restoration, but it also stimulated the invention of engine-driven mallets for gold foil compaction. Bonwill designed such a mallet wherein a small cylinder of hardened steel set in the circumference of a wheel, with its axis at right angles to the plane of the wheel and protruding slightly beyond its edge, struck once in each revolution the end of a long plugging instrument that passed through the handle of the appliance. When its patents expired, this mallet was widely imitated and many other mallets were produced which used various means to translate rotational energy into impact energy. Pneumatic mallets were also developed, usually operated by a pedal that either compressed a rubber bulb or worked a small bellows or a small air pump. One German instrument used the pedal and flywheel of a dental foot engine to drive a small double-acting air pump. In all instances, the air was led by a small bore tube to the mallet in which it generally forced a weighty piston along a cylinder to strike the end of a plugging instrument.

The disadvantages of gold foil fillings lie in their conspicuous colour and, in live teeth, their capactiy to conduct heat, although the effect of the latter can be greatly reduced by lining the cavity with dental cement. Among their advantages are the inert nature of the material, the way in which it can be forced against the cavity edge to make a good seal and the fact that fillings can easily be polished and burnished to a very smooth surface finish. Some years ago, correspondents to a dental journal reported gold foil fillings which had remained sound for several decades.

In the U.S.A. there are still enough proponents of the art or skill of filling cavities in teeth with mechanically compacted pure gold foil to support the activities of a Society of Gold Foil Operators.

\section{The Search for an Alternative to Gold Foil}

The arduous and time-consuming process of filling a cavity with gold foil involves much stress for both patient and operator, especially if the filling extends into more than one surface of a tooth. During the last two decades of the nineteenth century and the first few years of this century, a number of dentists therefore sought to devise some alternative means of using gold to achieve the same result.

A method of inlaying gold into cavities appears to have been the aim of several experimenters in the U.S.A. A procedure of this type was seen as having the advantages that the inlay might be made in the absence of the patient, and possibly by a 'mechanic' rather than the dentist, to fit a model taken from an impression of the prepared cavity. The finished inlay could be cemented into place at the patient's next visit. For some years, porcelain inlays had been made by swaging a thin platinum foil directly into the cavity or into a plaster model of the cavity, lifting out this so-called platinum matrix and filling it with porcelain powder which was then fused in a furnace. Attempts were made to adapt this method by making a similar platinum matrix, melting gold solder into it to fill it and cementing the resultant inlay into place. However, the method was suitable only for cavities involving one surface of a tooth and these were the easiest to fill with gold foil.

Another intricate method that was proposed, used a gold matrix swaged against the walls of the cavity and filled with a material resembling sealing wax, the exposed surface of which was carved to the shape of the missing external surface of the tooth. From this, a die and counter-die were made and used to reproduce this surface shape in thin gold plate. This shape and the gold matrix were then soldered together to make a hollow inlay.

\section{Lost Wax Casting}

Others attempted to use lost wax methods with varying degrees of indifferent success. B. F. Philbrook, dissatisfied with the way in which his 
W. H. Taggart's development of the lost wax process for casting dental prostheses and the machine that he designed for this purpose are often seen as constituting the basis of modern practice. The widespread adoption of investment casting in dentistry and as a major manufacturing technique for gold jewellery bear witness to Taggart's ingenuity

amalgam fillings crumbled, attempted to make soft, fusible metal inlays by a lost wax process. In 1896, he fitted several white metal inlays and one gold inlay and the following year he read a paper about his method to a local dental society (17). George B. Martin demonstrated in 1897 gold dummy or artificial teeth, called 'pontics', for use on fixed bridges; these were soldered to gold crowns on the abutment teeth. He carved his pontics out of wax to fit between the abutment teeth on a plaster model, attached a flat gold sprue and invested them in a two-part mould made of plaster and asbestos. This was so shaped that when the sprue had been removed, the wax burned out and the gold melted in a depression above the resultant void, pressing the mould to close it would push the molten gold into the void. About 1900, J. G. Schottler used a method to restore the biting edges of front teeth by placing a platinum wire in the root canal, building the required shape on the tooth with wax, inserting a warmed pin into the surface of the wax to lift it out and placing it in a bulk of investment. When the investment was set he carved a depression around the pin until the wax was reached, withdrew the pin and burned out the wax. Gold was melted in the depression and pushed into the void with a metal implement or a carbon rod. Also, John A. Lenz devised a method for lost wax casting a gold chewing surface onto a gold band made to fit around a tooth and obtained a patent for it in 1906.

\section{Taggart's 'New and Accurate Method'}

However, to a meeting of the New York Odontological Society on January 15, 1907, William H. Taggart of Chicago read a lecture entitled 'A New and Accurate Method of Casting Gold Inlays' in which he described a lost wax technique which can truly be said to have revolutionized restorative and prosthetic dentistry (18). The process used no new principle and some aspects of it had been anticipated by other dentists, but, by careful experiment over a period which he stated later was 15 years, Taggart had overcome a variety of physical and technical problems to attain great precision. He described and then demonstrated this process in full that evening. It has remained fundamentally unchanged since then,

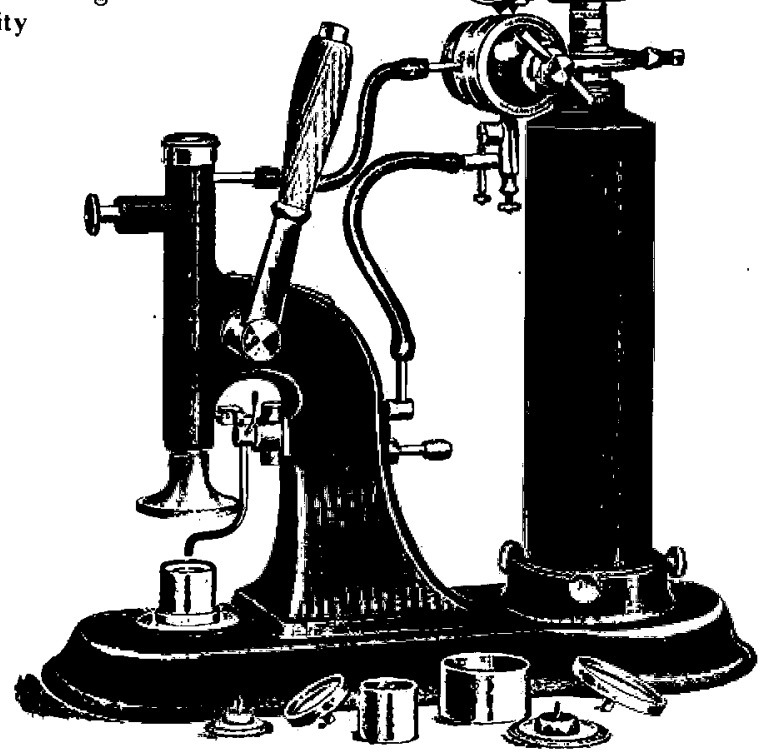

although it has been improved in some respects as new knowledge has been acquired. Contemporary accounts of the meeting describe the fascination of the audience, the prolonged applause and the admiration voiced by participants in the discussion for what he had put before them (19).

The apparatus used by Taggart employed a nitrous oxide and gas blowpipe to melt gold very rapidly to what he described as 'the boiling state', at which point a lever was pulled down, switching off the blowpipe and applying compressed nitrous oxide to the molten metal to force it into the mould. In addition to devising his casting machine, Taggart introduced a number of ingenious features of his own invention. The wax with which the model of the inlay was made in the prepared cavity in the tooth was of selected composition and had been repeatedly filtered while molten to remove particles of foreign matter. The wax model was removed from the cavity with the aid of a wire inserted into it while it was warm. The wire was then inserted into a dome-shaped boss in the centre of a metal disc, and a metal cylinder of suitable size was placed around it and filled with an investment material mixed with water. This material was devised by Taggart after much experiment and contained a high proportion of graphite. When the investment had set hard, the domed disc was removed, the wire warmed and pulled out of the wax and the metal cylinder carefully warmed until the wax was melted and absorbed into the investment. This left a void the shape of the inlay with a sprueway leading down to it from a depression in which the gold could conveniently be fused. 
The simple casting apparatus (1op), developed by Solbrig, utilized steam pressure which was released when a moist asbestos pad, fitted into the lid, was lowered onto the hot monld to force the molten gold into the cavity

The sinılified hand-held version (bottom), akin to pliers and relying on the same principle as the bench-top model, was developed for the production of small gold castings such as inlays

The response of the dental profession was rapid. As news of Taggart's method and the account of it in the journals spread, dentists from all over the U.S.A. ordered his casting machine. He was a skilful mechanic and a painstaking experimenter satisfied only with the best results he could achieve but, unfortunately, he had neither facilities to manufacture his machine in quantity nor the ability to organize them, even though he had patented both the machine and the process. While he was endeavouring to make suitable arrangements with a manufacturer, dentists impatient to produce gold castings for inlays, bridges and dentures invented other forms of casting apparatus and used them. When at last he was ready to sell his machine, Taggart found that the market for it had gone and, disappointed by the loss of the profits he had hoped for, he entered into long and complicated litigation aimed at forcing dentists to pay him for a licence to use the method. Powerful opposition to him was organized among American dentists and the credit that he rightly deserved for his great achievement was largely denied him.

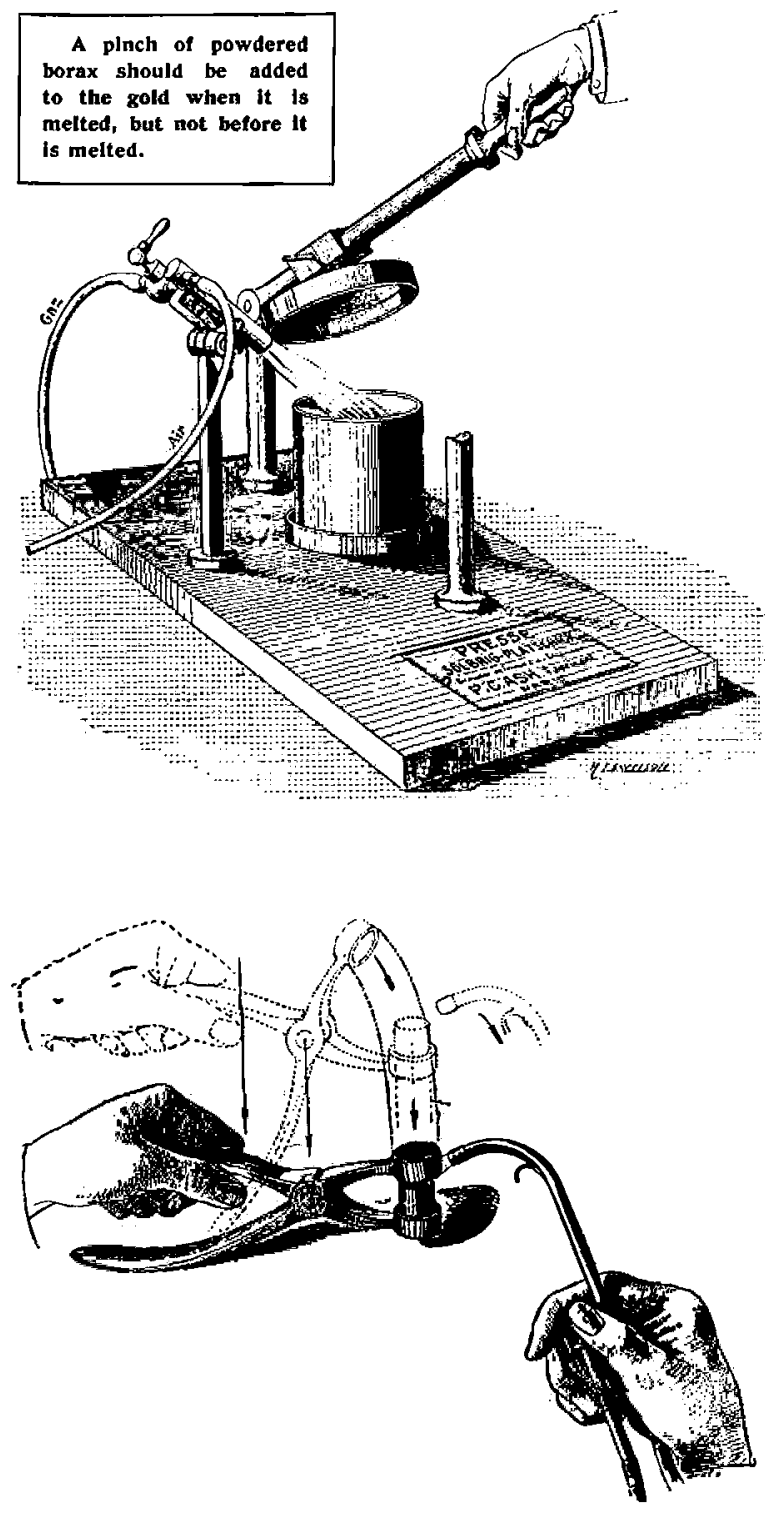

A modern cast gold alloy bridge with the working model of the palient's teeth

Photograph by courtesy of Professor J. Bates, Dental School and Hospital, Cardiff, and the Metals Society, London

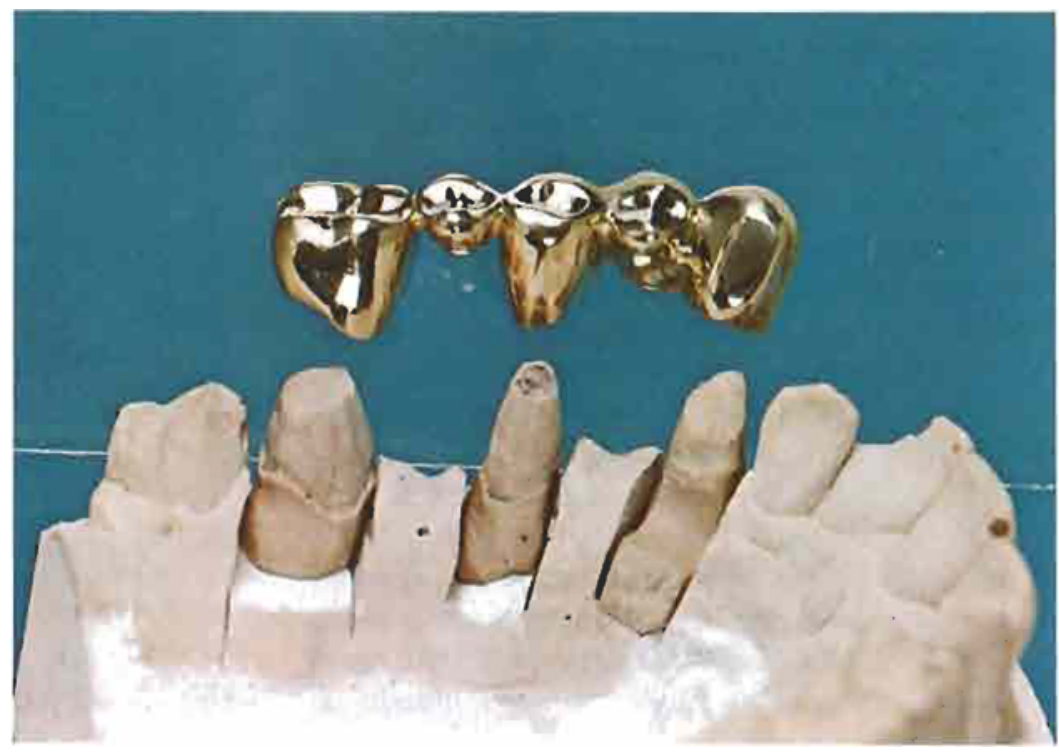




\section{Other Lost Wax Casting Apparatus}

Taggart's results immediately stimulated interest in lost wax casting of gold and new developments followed. Thus, a centrifugal casting machine was invented by A. Jameson and was on sale by 1910 . Several machines were also produced which used a tank of compressed air in place of Taggart's nitrous oxide to force the metal into the mould. Two air pressure machines were produced in Great Britain, the first of them, that of the Dental Manufacturing Company, being patented in 1908. In a variant of the compressed air method, introduced in the U.S.A. by L. E. Custer, the casting cylinder was enclosed in a glass dome and the gold was melted by means of an electric arc. As soon as the gold was molten, compressed air was admitted to the dome. Other machines depended for their action on the application of a partial vacuum to draw the air from the mould and to assist the molten gold to flow into it as a result of the pressure differential.

At about the same time that Taggart was engaged in the experiments that led to his announcement in 1907, a Dr. Solbrig, in Paris, was also studying the production of gold inlays by a lost wax method (20). Solbrig produced a machine in which a pad of moist asbestos in a metal cap could be brought down on to the top edge of the hot casting cylinder as soon as the gold was molten, when the pressure of the resulting steam forced the gold into the mould. Taggart used a cool mould and Solbrig appears to have been the first to cast into a hot mould. The latter author stated that the moment to fuse the gold and bring down the damp asbestos pad was when the glow viewed down the sprue hole was a bright red. Before the end of 1907, Solbrig also introduced his casting pliers which achieved enormous popularity for the rapid production of small inlays.

\section{Improvements to Dental Casting}

J. G. Lane (21), having observed that castings made by Taggart's method were consistently too small, attributed this to contraction of the gold on cooling. $\mathrm{He}$ developed an investment material containing a high proportion of silica which, when heated to about $750^{\circ} \mathrm{C}$, expanded and compensated for the shrinkage. Although accuracy of casting was much improved by Lane, the method was less successful than he claimed. The next improvement was made by C. S. van Horn who reviewed progress to date and described (22) his method of warming the wax pattern to a temperature at which its expansion was sufficient to compensate for the subsequent contraction of the gold, immersing it in investment mixed at that temperature and maintaining the temperature constant until the investment was fully set.
Subsequent research by many workers has produced better machines, waxes, investments and gold alloys which have led to the reliable methods of the present day and their precisely predictable results. In the late 1920 's, cobalt-chromium alloys were first introduced for casting dentures by the lost wax method and their proponents suggested that they would be cheaper and that dentures made of them would have better physical properties, in particular greater strength, than those made of gold alloys. However, about 20 years passed before some of the difficulties of casting cobalt-chromium alloys with consistent accuracy and of finishing the castings were solved. By that time, the expense of the method was such that gold alloy castings could often be produced more cheaply. Although subsequent increases in the cost of gold have made cobalt-chromium alloys more formidable rivals for denture work amongst dental practitioners and patients, gold alloys are still the materials of choice for inlays, crowns and bridges.

\section{References}

I H. Humphreys, 'Early Problems of Dental Prosthesis', \%. $R$. Coll. Surg, Edinburgh, 1966, 11, 253-259

2 H. Junker, 'Giza, Bericht über Grabungen auf dem Friedhof des Alten Reiches', Wien/Leipzig, 1929

3 W. Hoffmann-Axthelm, 'Zur Geschichte des Zahnersatzes', Quimessenz, 1969, 12, 131-136

4 F. Filce Leek, 'Did a Dental Profession exist in Ancient Egypt?', Dent. Delin, 1969, 20, (Spring), 18-21

5 W. Hoffmann-Axthelm, 'Is the Practice of Dentistry in Ancient Egypt an Archaeological Fact?', Bull Hist. Dent., 1979, 27, 71

6 V. Guerini, 'A History of Dentistry', Lea and Febiger, Philadelphia and New York, 1909 (Reproduced by Liberac, Amsterdam, 1967)

7 W. H. Ryff, 'Die Grosse Chirurgei', Frankfurt, 1545

8 P. Fauchard, 'Le Chirurgien Dentiste', Jean Mariette, Paris, 1728

9 A. Paré, 'Oeuvres Complètes', Paris, 1573

10 C. Mouton, 'Essai d'Odontotechnie, ou Dissertation sur les Dents Artificielles', A. Boudet, Paris, 1746

11 G. d'Arcoli, 'Practica seu Exposito', Padua, 1480

$12 \mathrm{G}$. da Vigo, 'Practica Copiosa in Arte Chirurgica', Rome, 1514

13 R. Arthur, 'A T'reatise on the Use of Adhesive Gold Foil', Jones, White and McCurdy, Philadelphia, 1857

14 J. Boyes, 'Edinburgh Dentists and Porcelain', Univ. Edinburgh 7., 1971, (December), 123-126

15 C. Spence Bate, 'A Review of the Scientific Progress of Dental Surgery from 1771 to $1883^{\prime}, \mathcal{H}$. Br. Dent. Assoc., 1883, 4, 493-501 and 531-546

16 B. L. Thorpe, 'A Biographical Sketch of M. H. Webb', Dent. Rev., 1904, 18, 155-162

17 B. F. Philbrook, Trans. Iowa State Dent. Soc, 34th Annu. Meet., May 4 to $7,1897,227-280$

18 W. H. Taggart, 'A New and Accurate Method of Casting Gold Inlays', Dent. Cosmos, 1907, 49, 1117-1121

19 Proc. New York Odontol. Soc,, Dent. Cosmos, 1907, 49, $1162-1172$

20 B. Platschick, 'Dr. Solbrig's Method of Gold Casting', Ash O. Girc., 1907, (Sept./Dec.), 338-352

21 J. G. Lane, 'Cast Gold Inlays', Dent. Dig., 1909, 15,489-499

22 C. S. van Horn, 'Casting: A Review and a Commentary Including a Technique which Makes Possible a Casting of the Same Size as the Wax Pattern at Body Temperature', Dent. Cosmos, 1910, 52, 873-881

The second part of this article will be published in the October 1980 issue of Gold Bulletin. 